\title{
Linking City-level Input-output Table to Urban Energy Footprint: Construction Framework and Application
}

Heran Zheng ${ }^{1}$, Jing Meng ${ }^{2 *}$, Zhifu $\mathrm{Mi}^{3}$, Malin Song ${ }^{4}$, Yuli Shan ${ }^{5}$, Jiamin $\mathrm{Ou}^{1}$, Dabo Guan ${ }^{1 *}$

1. Water Research Centre, School of International Development, University of East Anglia, Norwich NR4 7TJ, UK.

2. Department of Politics and International Studies, University of Cambridge, Cambridge CB3 9DT, UK.

3. The Bartlett School of Construction and Project Management, University College London, London, WC1H 0QB, UK.

4. School of Statistics and Applied Mathematics, Anhui University of Finance and Economics, Bengbu, 233030, China.

5. Tyndall Centre for Climate Change Research, School of Environment Sciences, University of East Anglia, Norwich NR4 7TJ, UK.

Correspondence Email: Dabo.guan@uea.ac.uk (Dabo Guan),jm2218@cam.ac.uk (Jing Meng); Additional Information: The authors declare no competing financial interests.

Author contribution statement: H.Z., J.M designed the research; H.Z. wrote the main manuscript text; D.G., Z.M, J.O conceived the research; and H.Z, J.M, Z.M \& Y.S provided the data and methods. All authors reviewed the manuscript. 


\begin{abstract}
Multi-region input-output (MRIO) models have become increasingly important in economic and environmental analysis. However, the current resolution of most MRIO models fails to capture the heterogeneity between sub-regional level, especially in cities including both urban and rural areas. The lack of city-level MRIO tables has decelerated the growing number of city-level studies and hampered the understanding of the relationship between urban growth and consumption and teleconnection to other regions. In this paper, we propose a partial survey-based multiple-layer framework for a city-level MRIO table compilation. This framework can effectively address a large number of data processes and retain consistency between layers. Using the framework, we first compile a nested Hebei-China city level MRIO table and then apply into accounting city-level energy footprint of North China urban agglomeration. Our results present the critical role of Hebei cities in exporting energy use for China in 2012 and quantifies energy use embodied in goods for the domestic trade. Tangshan, Shijiazhuang, and Handan are distinctive cities in energy supplies for other regions, for both less developed and developed regions. This multiple-layer framework represents a feasible approach for developing city-level MRIO models and offers the possibility to analyse global trade at the city-level with the limited data.
\end{abstract}

Keywords: MRIO table compilation, City level, China, Jing-Jin-Ji urban agglomeration, bottom-up approach 


\section{Introduction}

Many goods and services are now outsourced across borders and understanding cross-regional trade is crucial for local decision making (Dietzenbacher, Los, Stehrer, Timmer, \& de Vries, 2013; Kuishuang Feng et al., 2013; Oosterhaven, Stelder, \& Inomata, 2008). Multi-region input-output models (MRIOs) have been widely recognised as good assessment tools that can track the supply chain and capture regional homogeneity as well as heterogeneity, thus accurately reflecting environmental and socioeconomic implications (Bachmann, Roorda, \& Kennedy, 2015; Dietzenbacher, Lenzen, et al., 2013; Miller \& Blair, 2009; Wang, 2017). Over the recent decade, many efforts have been made to develop MRIO databases at international level: EORA (Manfred Lenzen, Kanemoto, Moran, \& Geschke, 2012; Manfred Lenzen, Moran, Kanemoto, \& Geschke, 2013), WIOD (Dietzenbacher, Los, et al., 2013), GTAP-MRIOT (Peters, Andrew, \& Lennox, 2011), and Asian International Input-Output Table produced by IDE-JETRO(B. Meng, Zhang, \& Inomata, 2013). Or subnational level such as China (Liu, Li, Liu, Tang, \& Guan, 2015; Mi et al., 2017; Z. Zhang, Shi, \& Zhao, 2015), the UK (Yu, Hubacek, Feng, \& Guan, 2010), Japan (Nakano \& Nishimura, 2013; Yamada, 2015), and Australia (Manfred Lenzen et al., 2014). Although these databases have helped gain a comprehensive understanding of regional disparities and spillover effects in interregional and international trade, none of current MRIOs (national or provincial) cannot offer insights in assessment at the local scale, particularly at the city level. This widens a massive gap between research resolution and government decision-making, especially in the context of increasing significance of cities with regard to economic growth, energy consumption, resources management, and public health (Nair, George, Malano, Arora, \& Nawarathna, 2014; Shan et al., 2017; Xia et al., 2017).

Detailed information at the city level could be much more meaningful to local governmental decision making than aggregated information from regional or international MRIOs (Wang, 2017). The lack of high-resolution city-level MRIOs 1) undermines the understanding of the disparities between cities within a single region or across regions, especially for large geographical regions, and 2) fails to comprehensively capture the linkages between trade partners in cities (including at the provincial or national level) and identify the role of cities role in supply chains at multiple scales (Bachmann et al., 2015). The disadvantages at city level MRIO particularly compromise global decarbonised initiatives, as cities are the largest source in global primary energy consumption and $\mathrm{CO} 2$ emissions (Dhakal, 2010; Mi et al., 2016). It requires accurate and comprehensive carbon accounting, with respects to the regional or global supply chain, and thus identify mitigation priorities and responsibilities along the supply chain(T. O. Wiedmann, Chen, \& Barrett, 2016). Unfortunately, city-level studies now employ the downscaling method from national IO tables by proxy data (e.g. demographic data) to capture the heterogeneity for socioeconomic and environmental implications through the supply chain (Caro, Rugani, Pulselli, \& Benetto, 2015; Chavez \& Ramaswami, 2013; Moran et al., 2018; Paloheimo \& 
Salmi, 2013). These approaches are likely to produce biased results because of the assumption of homogeneity in production technology, and customer preferences between nations and cities.

Although the importance of high-resolution MRIOs has been well acknowledged, compiling MRIOs can be time consuming, involving an exhaustive and costly amount of data (T. Wiedmann, Wilting, Lenzen, Lutter, \& Palm, 2011); thus, this process is generally limited by the availability of comprehensive and consistent survey data, especially at the city level (Manfred Lenzen et al., 2014; Lin, Hu, Cui, Kang, \& Ramaswami, 2015; Minx et al., 2013). Therefore, non-survey and partialsurvey methods that have more reasonable data requirements have frequently been used for IO table construction (Kowalewksi, 2015; Yamada, 2015). Non-survey methods refer to use series of modelling including input-output table estimation and trade flows estimation to estimate targeted IO table, while partial-survey methods use some survey-based data as either baseline or constrain to estimate targeted IO table. However, non-survey methods have been often criticised for poor accuracy and reliability (Lehtonen \& Tykkyläinen, 2014; Riddington, Gibson, \& Anderson, 2006). Therefore, partial-survey methods that incorporate non-model information in a non-survey model have been advocated (Lahr, 1993) and widely applied in many global and regional-level MRIO databases, such as WIOD, IDE-JETRO, and the China MRIO. The conventional steps of MRIO table construction with partial-survey methods can be summarised as follows: first, an initial estimate matrix and constraints are built using non-survey methods, after which mathematical optimisation operations (e.g., the RAS method) are used or disaggregation of multipliers to yield a final MRIO table or multipliers that meet the study requirements (Oosterhaven, 2005; Temurshoev, Webb, \& Yamano, 2011). These steps work for regional or national MRIO compilations with reasonable workloads. However, they are hardly feasible for city-level MRIO compilations, which are enormously dataintensive, and in which development would be greatly challenged by the use and processing of substantial amounts of input data (Manfred Lenzen et al., 2012). For example, in total, nearly 300 cities in China must be included during compilation of a city-level MRIO table; this table would be at times larger than the province-level MRIO tables compiled by larger regions or the 30 provinces (Ichimura \& Wang, 2003; Liu et al., 2015; State Information Center, 2005; Wang, Geschke, \& Lenzen, 2017; Y. Zhang \& Qi, 2012). Overcoming these challenges thus represents a key challenge in compiling city-level MRIO tables. To our knowledge, only IMPLAN and the Industrial Ecology Virtual Laboratory (IELab) technology that was recently developed by Lenzen et al. (2014) attempt to construct city-level MRIO tables. The former is based on double constraint gravity model, which assumes identical proportion of supply to demand and data from commodity flow survey, by US government. The latter overcomes these limitations and offers a flexible compilation structure for city-level MRIOs based on 11 non-survey methods. This framework has been used to develop a citylevel MRIO table for Australia (Manfred Lenzen et al., 2014, 2017) and a Jing-Jin-Ji urban agglomeration for China using Flegg's location quotient methods (Wang, 2017; T. Wiedmann, 2017). 
The framework enables the successful estimation of a city-level MRIO table from national-level data while maintaining consistency with the national table. Unfortunately, the construction methods largely follow a top-down philosophy that scales an existing high-level IO table. Moreover, the assumption of homogeneity in technology and consumption between nations and regions is not always realistic, especially for a large country with high regional heterogeneity such as China (Bonfiglio \& Chelli, 2008; Kowalewksi, 2015). And the assumption of minimizing of inter-regional cross-hauls always turns out to be biased results (Oosterhaven, 2005).

In contrast to the top-down procedure in the IElab framework, in this paper, we propose a bottom-up methodology for city-level MRIO table compilation based on partial-survey methods. We are based on the city-level input-output table that is compiled by local statistics agency through survey method, while the interregional trade matrix is estimated by the gravity model. The primary objective of this study is to overcome the problems presented by processing large amounts of data while preserving information from the city-level data. For the remainder of this paper, we use the term "city-level" to refer to a level smaller than the provincial level (such as a city, county, or even village), while we use the term "region" to indicate a province or country. It is notable that there are different understanding in term "city" based on different backgrounds, where the city in many countries refers to built-up areas but in China the city includes both urban and rural areas, more close to the term "sub-region". To avoid misunderstanding, the city level in this paper refers to the sub-regional level if not specifically define, which includes both urban and rural areas, because our demonstration is mainly based on China's data. In the following sections, we present the conceptual framework we use to develop city-level MRIO tables. Next, as a case study, we present the detailed procedure for city-level MRIO table compilation for the Jing-Jin-Ji urban agglomeration using the framework proposed in the paper with validation checks. Finally, we conclude our work by stating the limitations of the study and discussing challenges and future work. It is notable that MRIO table compilation method could be largely different based on kinds of data compiler have. The MRIO table compiled in developed countries, such as the USA, might be applicable to the developing and emerging countries. The framework applied in our paper could be helpful for countries which have limited data at regional and sub-regional level. 


\section{Multiple-layer framework and methodology}

To compile large-scale MRIO tables, a conventional approach using the partial-survey method requires that all regions must be included within certain boundaries, which results in two hurdles. 1 . limited information at the city level. Intact information for all regions or a majority of regions to build MRIO table could be very harsh at the sub-regional level. For example, city-level single IO tables are always in shortage, unlike national level singe IO tables that are published by the most of major countries. This hurdle suggests that city-level MRIO table cannot be compiled if without intact information, which massively restricts the increasingly booming city-level research because collecting data could be extremely costly in time and money; 2. Large workloads in the compilation. Given the case of creating the MRIO table in the EORA database involved compiling 187 countries with international trade links; in total, this included $5 \times 10^{6}$ data points (Manfred Lenzen et al., 2013). Even if all the needed information at the city level can be collected, workloads could be even greater, making data input and processing impractical.

To overcome these difficulties, we propose a simple but feasible way which to decompose the compilation processes into multiple layers based on reasonable workloads and data availability; the underlying idea is to break down the huge workloads into pieces, like jigsaw puzzles. Hence, the biggest advantages are opposite the difficulties: Using the available data to construct parts of citylevel MRIO table, which would be a compilation platform for further compilation when data is available, and reducing the workloads when only to compile part of city-level MRIO table. 


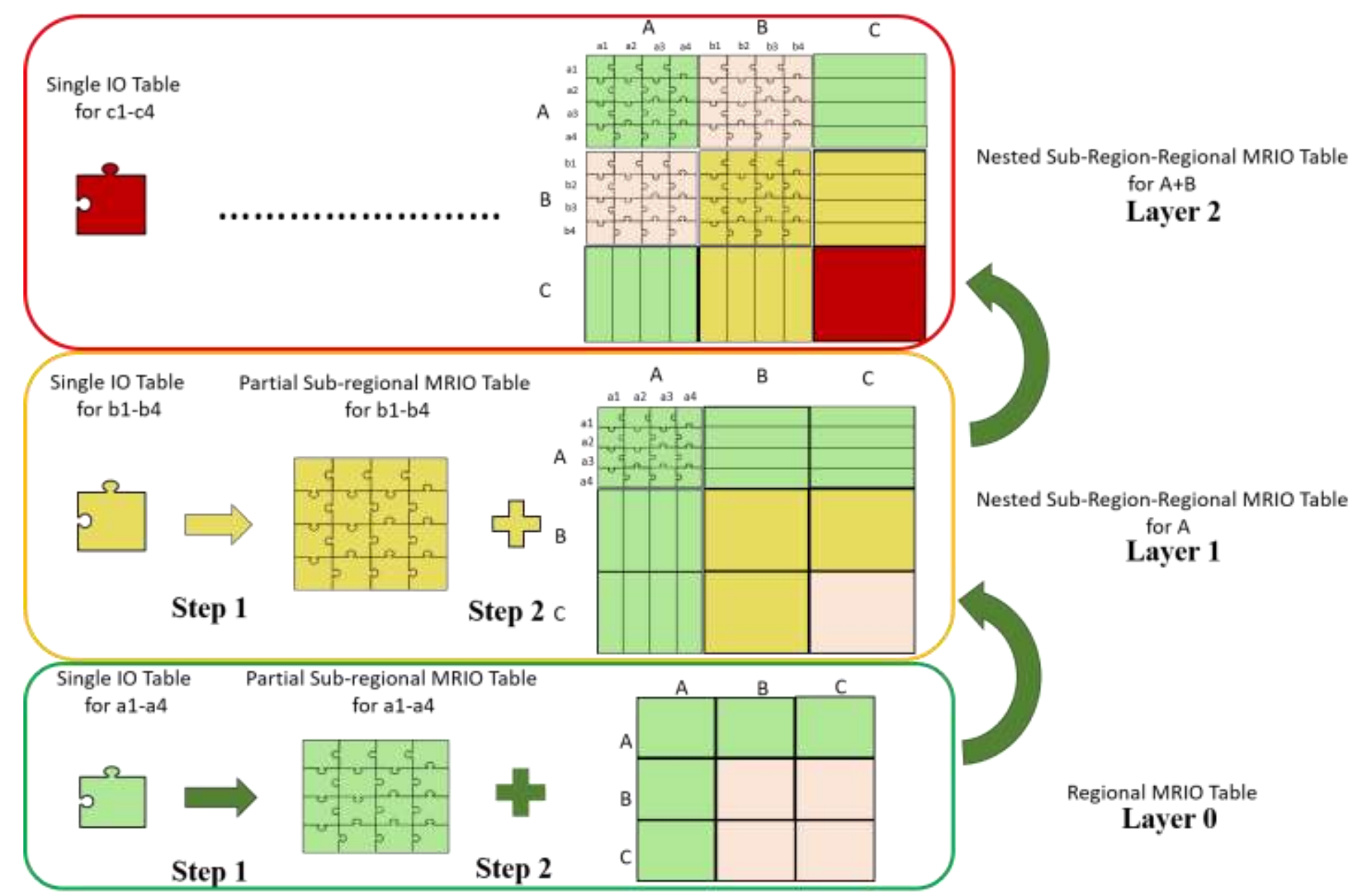

Figure 1 The diagram of compiling city-level MRIO table. The case of 3 regions, with total 12 city-level is demonstrated. For simplicity, only the intermediate transaction matrix and the final demand matrix are shown in the producer figure. After 3 iterations, the whole city-level MRIO table for 12 citylevel can be compiled. 
We demonstrate the compilation process through assuming to compile a city-level MRIO table for 3 regions that consist of 4 city-level for each, as shown as Figure 1. Two steps are employed to compile the city-level MRIO table. In step 1, we start by constructing partial city-level MRIO table for the given region A by the partial survey methods. Here single IO tables for all city-level in region A are required, thus single IO tables for a1, a2, a3, a4. The term "partial" here is relative to the full MRIO table from the perspective of a country, for example, city-level MRIO for all Chinese cities is called as full city level MRIO table, but city-level MRIO for some cities is called partial city level MRIO table (details are seen Supplementary). In step 2, the partial city-level MRIO table developed in step 1 would be treated as the elementary matrix to link with regional MRIO table, and further, reconcile into nested city-region MRIO table consisting of city-level (a1, a2, a3, a4) and regions (B, C). The linkage between the partial city-level MRIO tables into the regional MRIO table based on the assumption of an identical trade coefficient of regional MRIO table. The assumption of an identical trade coefficient is adopted by linking the partial city-level MRIO tables and the regional MRIO tables. This is a well-accepted assumption that has been applied in many MRIO table construction efforts (K. Feng et al., 2013; Mi et al., 2017; Wang et al., 2017). The trade coefficient for city-level and other regions (e.g., provinces) is equal to the trade coefficient between the parent region of the city-level and other regions. The resulting nested MRIO table can be used as a platform for next layer, into which a new partial city-level MRIO table can be inserted, as shown in Figure 1 Layer 1. For example, to get the full China city-level MRIO table, the two procedures would be iterated for the other regions until all the regions were replaced by their city-level MRIO tables.

The advantage of breaking down the MRIO table construction into partial city-level is that the stepwise construction avoids numerous trade flow estimates at the city level. Considering that the city-level IO tables within a region are usually fragmented, decomposed city-level MRIO table construction allows the construction of tables for the city-level that already have data and promotes city-level research in available city or regions without the full city-level MRIO table. Moreover, the framework can maintain consistency between the city-level MRIO tables and the partial city-level MRIO tables, given that all partial MRIO tables are integrated into the regional MRIO table. Thus, the multiple-layer framework offers flexibility and is suitable for large-scale MRIO development; it is particularly helpful for global city-level MRIO table development, as city-level information in the world is limited and impossible to be prepared at once. 


\section{Construction of the Jing-Jin-Ji urban agglomeration MRIO table}

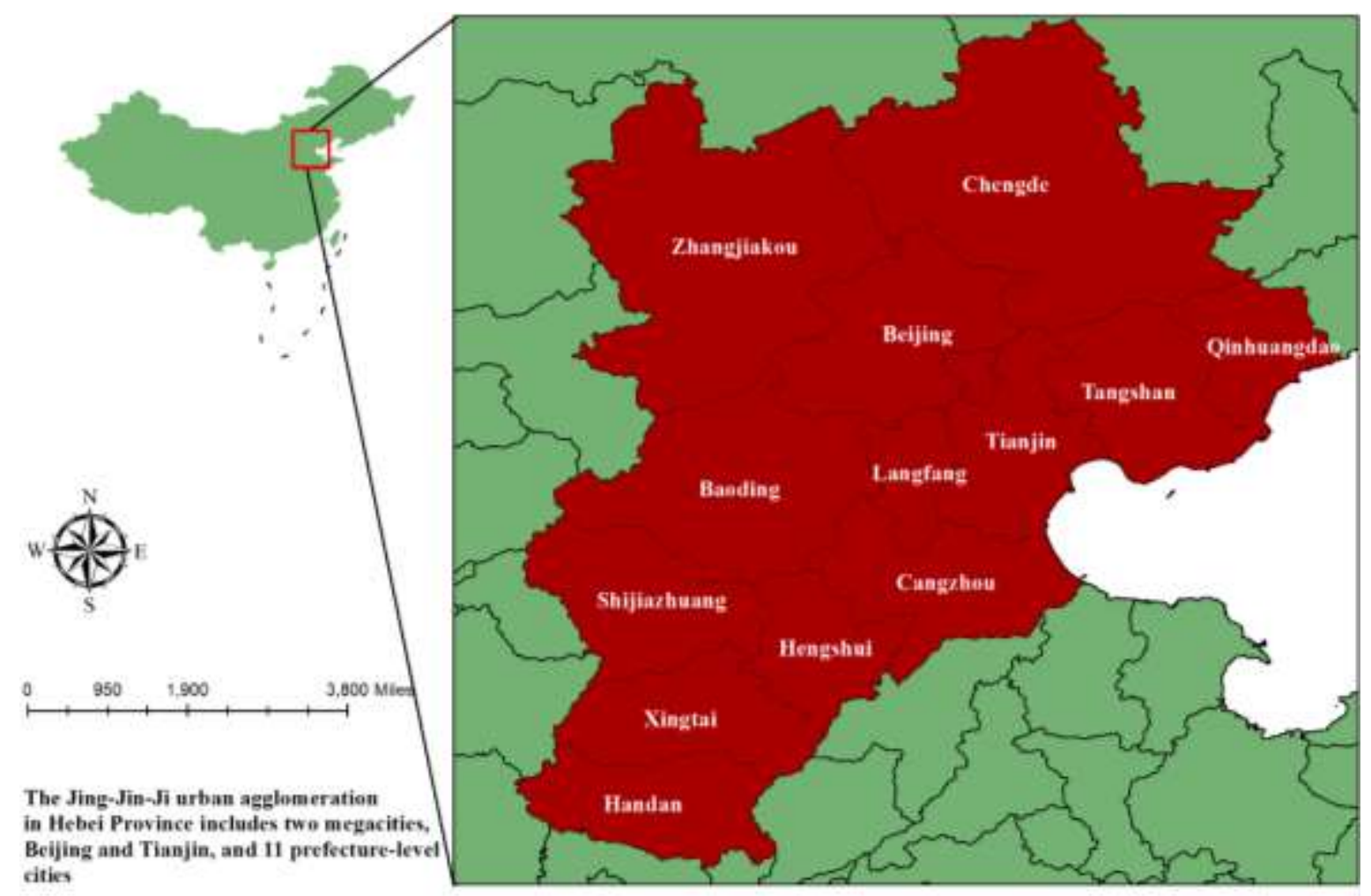

Figure 2. The thirteen cities in the Jing-Jin-Ji urban agglomeration.

\section{Data requirement}

Jing-Jin-Ji urban agglomeration consists of Beijing, Tianjin and Hebei province. Beijing and Tianjin are megacities which are granted as provincial status, while Hebei province consists of 11 cities. In total, 13 cities are included in the urban agglomeration (Figure 2). Single city IO tables are an basic component in the bottom-up approach to compiling partial city-level MRIO tables. In this case study, the data used were the set of 2012 IO tables for the 11 cities in Hebei, which were compiled by the Hebei Statistics Bureau (Hebei Statistics Bureau, 2015). The 11 cities are Shijiazhuang, Tangshan, Qinhuangdao, Hengshui, Langfang, Zhangjiakou, Xingtai, Handan, Cangzhou, Baoding, and Chengde. In total, 42 sectors, including 27 secondary sectors, 14 tertiary sectors and 1 primary sector, were covered by the IO tables. The IO tables were compiled using the purchaser's value with the competitive type. In this type, it is assumed that imported goods can substitute perfectly for domestic goods; thus, the intermediate inputs are presented as an aggregate value that includes domestic intermediate inputs and imported intermediate inputs (Lau, 2010).

In addition to the city-level IO table, the Hebei province IO table for 2012 was also required; these data were collected from the National Bureau of Statistics of China (NBS). The sector classification and IO table type in the provincial IO table are identical to those in the city IO tables. It is notable that 
Hebei province IO table could not be replicated when aggregating over cities, because they are compiled by different statistics agencies based on their own data sources. China applied graded accounting systems to its different level economic statistics, which means statistics agencies at different levels do economic statistics independently. This leads to the discrepancy in economic statistics between different levels. Therefore, province data is not equal to aggregating city-level data. Following the harmonisation procedure outlined above, China's 2012 MRIO table, compiled by Mi et al. (2017), was collected from the China Emission Accounts and Datasets (CEADS) database (http://www.ceads.net/). It includes 26 provinces and 4 megacities (except Taiwan, Hong Kong, Macao, and Tibet, due to data availability) and has classifications for 30 sectors.

Energy consumption data for each sector and each region or cities in 2012 are also derived from CEADS database that is originally from China Energy Statistics Yearbooks 2013 for province level and Statistics Yearbook for each city 2013. The energy consumption data in Statistics Yearbook are divided by 17 energy types for 47 sectors (see details in Zheng et al., 2018). To aggregate 17 energy types with different units, we convert the 17 energy types into standard equivalent coal, based on the calorific value of various energy types, by coefficient factors found in China Energy Statistics Yearbooks 2013 and aggregate them together to have total energy consumption for each sector. However, energy inventory with 47 sectors are not same as the sector classification used in MRIOT, we adjust the sectors in energy inventory to concordance with the MRIOT sector classification, as same as Mi et al. (2017). Due to the discrepancy between Hebei province energy inventory and aggregation of 11 city-level energy inventories, we coordinate each city's energy inventory with provincial energy inventory. Using the proportion of each city's energy consumption in the aggregation of 11 cities, provincial energy inventory is scaled for each city.

Schematic of Breakdown sub-region 10 table

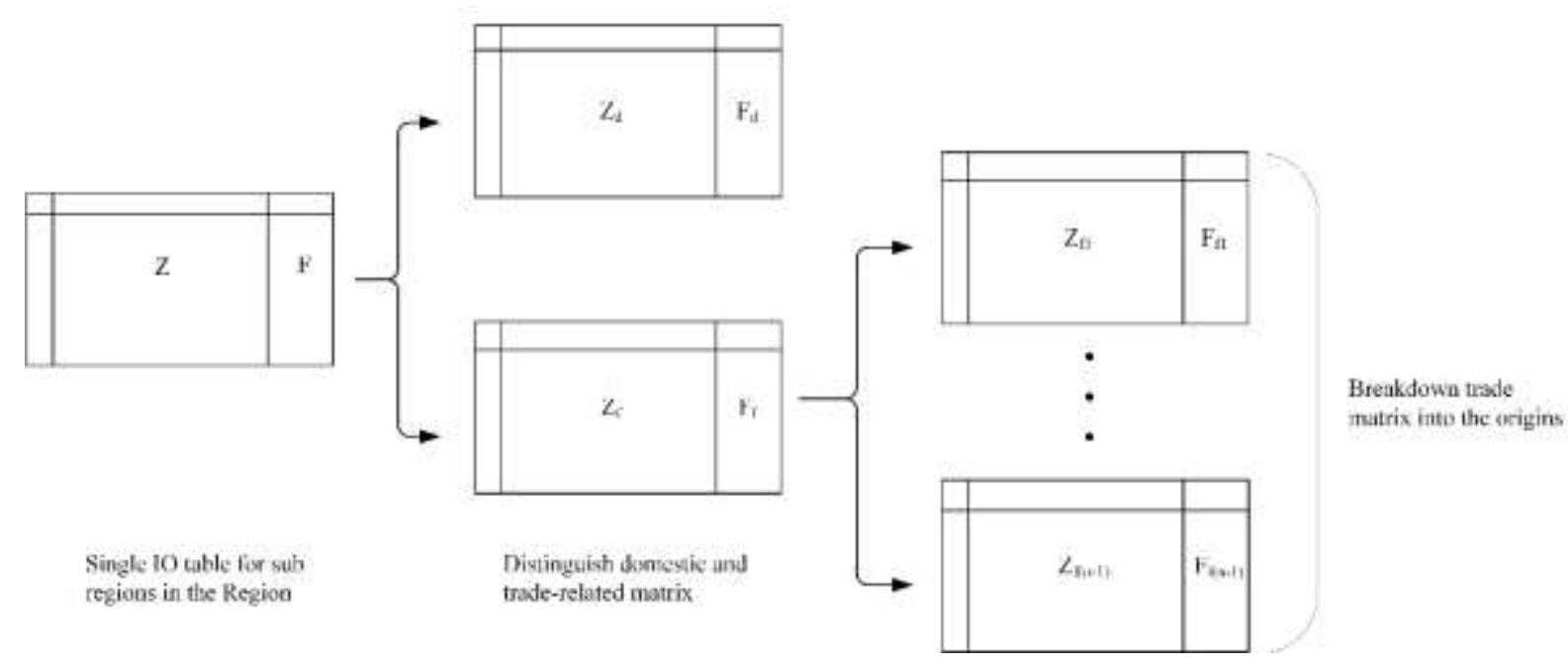


Figure 3. Schematic of distinguishing domestic and trade-related matrix.

\section{Method}

\section{Step 1: Partial city-level MRIO table compilation.}

This step is to make partial city-level MRIO tables from several single city IO tables. For clarity of presentation, we divided this step into four sub-steps:

\subsection{Dealing with re-export (imported goods were then exported).}

As re-exported goods are included in the IO table, we first identify if there have re-exports in the sectors by comparing the export in each sector with the total output, suggested by Dietzenbacher et al., 2013b. If export was larger than the output $\left(R E_{i}>0\right)$, we assume that re-exports exist, otherwise, there is no re-exports. Therefore, for a specific city c, its re-export can be checked with the following equation:

$$
\left\{\begin{array}{lr}
\widehat{R E}_{i}^{c}=\left(\mathrm{IM}_{i}^{c}+\mathrm{IF}_{i}^{c}\right)-\left(\sum \mathrm{M}_{i}^{c}+\sum \mathrm{F}_{i}^{c}\right) \\
R E_{i}^{c}=\widehat{R E}_{i}^{c} & \text { If } \widehat{R E}_{i}^{c}>0 \\
R E_{i}^{c}=0 & \text { If } \widehat{R E}_{i}^{c}<0
\end{array}\right.
$$

Where $\widehat{R E}_{i}^{c}$ is the parameter to examine if re-export exists for sector $i$ in cIty c. $R E_{i}^{c}$ is the re-exports in sector $i$ in the city c. $\operatorname{IM}_{i}^{c}$ and $\mathrm{IF}_{i}^{c}$ denote the imports from foreign countries to city $\mathrm{c}$ and the domestic inflow from other cities to city $\mathrm{c}$ in China for sector i, respectively. $\sum \mathrm{M}_{i}^{c}$ denotes the total intermediate uses of output from sector $\mathrm{i}$ in city $\mathrm{c}$ and $\sum \mathrm{F}_{i}^{c}$ indicates the total final demands for sector $i$ in city $c$, including household consumption, government consumption, fixed capital formation and changes in inventories.

After identification, if there is re-export for a sector in a city, this part would then be proportionally subtracted from inflows and imports (as well as outflows and exports) based on the ratio $r$ between inflows and imports (between outflows and exports), respectively. For the imports and inflows or exports and outflows, we use the "bar" symbol to denote the trade flows that exclude re-exports:

$$
\begin{gathered}
r_{i}^{I}=\frac{\mathrm{IM}_{i}}{\mathrm{IM}_{i}+\mathrm{IF}_{i}} \\
\left\{\begin{array}{c}
\overline{\mathrm{IM}_{i}}=\mathrm{IM}_{i}-r_{i}^{I} \times R E_{i} \\
\overline{\mathrm{IF}_{i}}=\mathrm{IF}_{i}-\left(1-r_{i}^{I}\right) \times R E_{i}
\end{array}\right.
\end{gathered}
$$




$$
\begin{gathered}
r_{i}^{O}=\frac{E X_{i}}{\mathrm{EX}_{i}+O F_{i}} \\
\left\{\begin{array}{c}
\overline{E X_{i}}=E X_{i}-r_{i}^{O} \times R E_{i} \\
\overline{\mathrm{OF}_{i}}=O F_{i}-\left(1-r_{i}^{O}\right) \times R E_{i}
\end{array}\right.
\end{gathered}
$$

\subsection{Extraction of domestic intermediate products and final demands;}

Since single city IO table is the competitive type which means the imports are enclosed in both intermediate production and final consumption, we first to extract the domestic intermediate products $\mathrm{Zd}$ and the final products Fd from the city IO tables ( $\mathrm{Z}$ and F), where $\mathrm{Zd}$ and $\mathrm{Fd}$ are not included. After removing the re-export, we followed previous studies (G. Q. Chen, Guo, Shao, Li, \& Chen, 2013; Guan et al., 2014; J. Meng, Liu, Guo, Huang, \& Tao, 2016; Ou et al., 2017; Weber, Peters, Guan, \& Hubacek, 2008) and assumed that each economic sector and final demand consume the same share of domestic and imported products.

Mathematically, this can be expressed using the following equation:

$$
\begin{aligned}
& Z_{d}=\left(1-\frac{\overline{\mathrm{IM}_{i}}+\overline{\mathrm{IF}_{i}}}{\left.X_{i}+\overline{\mathrm{IM}_{i}}+\overline{\mathrm{IF}_{i}}-\overline{E X_{i}}-\overline{\mathrm{OF}_{i}}\right) \times Z}\right. \\
& F_{d}=\left(1-\frac{\overline{\mathrm{IM}_{i}}+\overline{\mathrm{IF}_{i}}}{X_{i}+\overline{\mathrm{IM}_{i}}+\overline{\mathrm{IF}_{i}}-\overline{E X_{i}}-\overline{\mathrm{OF}_{i}}}\right) \times F
\end{aligned}
$$

Where $\mathrm{Z}$ and $\mathrm{F}$ are the intermediate matrices and final demand, respectively, derived from the IO table, and $X_{i}$ is the total output for sector $\mathrm{i}$ in the city. Using this procedure yields the diagonal of the intermediate matrix and the demand matrix in the MRIOs of the 11 Hebei cities. Correspondingly, the total trade matrix can be derived using $Z-Z_{d}$ and $F-F_{d}$, which includes domestic trade $\left(Z^{o s}\right.$ and $\left.F^{o s}\right)$ and foreign trade $\left(Z_{f}\right.$ and $\left.F_{f}\right)$ :

$$
\begin{aligned}
Z^{o s} & =\frac{\overline{\mathrm{IF}_{i}}}{X_{i}+\overline{\mathrm{IM}_{i}}+\overline{\mathrm{IF}_{i}}-\overline{E X_{i}}-\overline{\mathrm{OF}_{i}}} \times Z \\
F^{o s} & =\frac{\overline{\mathrm{IF}_{i}}}{X_{i}+\overline{\mathrm{IM}_{i}}+\overline{\mathrm{IF}_{i}}-\overline{E X_{i}}-\overline{\mathrm{OF}_{i}}} \times F \\
Z_{f} & =\frac{\overline{\mathrm{IM}_{i}}}{X_{i}+\overline{\mathrm{IM}_{i}}+\overline{\mathrm{IF}_{i}}-\overline{E X_{i}}-\overline{\mathrm{OF}_{i}}} \times Z
\end{aligned}
$$




$$
F_{f}=\frac{\overline{\mathrm{IM}_{i}}}{X_{i}+\overline{\mathrm{IM}_{i}}+\overline{\mathrm{IF}_{i}}-\overline{E X_{i}}-\overline{\mathrm{OF}_{i}}} \times F
$$

\subsection{Intercity trade flow estimate}

To estimate the intercity trade flow, the gravity model is applied in this study (Leontief \& Strout, 1963). The reason we choose is not only it widely used over 40 years, but also to maintain the methodology consistency with the regional MRIO table which it will be linked within step 2 . The model assumes that the trade flow between two regions $\left(T_{i}^{r s}\right)$ is a function of the total supply of the exporter $\left(E_{i}^{r o}\right)$, the total demand of the importer $\left(M_{i}{ }^{o s}\right)$, and the impedance in transportation costs, for which the distance between two regions is often used as a proxy $\left(D^{\gamma s}\right)$ (Marto Sargento, 2007; Riddington et al., 2006). The standard gravity model is as follows:

$$
T_{i}^{r s}=G^{\alpha} \frac{\left(E_{i}^{r o}\right)^{\beta_{1}} \times\left(M_{i}^{o s}\right)^{\beta_{2}}}{\left(D^{r s}\right)^{\gamma}}
$$

Where $G$ is the constant of proportionality with the weight $\alpha$. The parameters $\beta_{1}$ and $\beta_{2}$ are used to weigh the supply and demand for exporters and importers, respectively. $\gamma$ is the distance decay parameter. Practically, the equation is often presented in its logarithmic form:

$$
\ln T_{i}^{r s}=\alpha+\beta_{1} \ln \left(E_{i}^{r o}\right)+\beta_{2} \ln \left(M_{i}^{o s}\right)-\gamma \ln \left(D^{r s}\right)+\varepsilon
$$

Where $\ln T_{i}^{r s}$ is the endogenous variable, $E_{i}^{r o}, M_{i}{ }^{o s}$, and $D^{\gamma s}$ are the explanatory variables and the parameters $\alpha, \beta_{1}, \beta_{2}$ and $\gamma$ can be estimated by multiple regression. However, because limited information of trade at the city level, several assumptions are made for parameter estimates:

Assumption 1. Domestic trade destinations outside Hebei as a " $12^{\text {th }}$ city". This is because city IO tables do not distinguish between trade flow to cities inside and outside Hebei. For the 11 cities in Hebei, the total supply $E_{i}{ }^{r o}$ and total demand $M_{i}{ }^{o s}$ respectively refer to the domestic outflow $\overline{\mathrm{OF}_{i}}$ and the domestic inflow $\overline{\mathrm{IF}_{i}}$, including the flow from cities within Hebei and from cities outside Hebei, which can be directly determined from the city IO tables. For the $12^{\text {th }}$ city, we derive trade data from the 2012 Hebei province IO table; the inflow and outflow are the domestic trade flows from outside Hebei. Therefore, the inflow derived from the Hebei IO table can be treated as the outflow for the $12^{\text {th }}$ city, while the outflow in the Hebei IO table would be treated as the inflow for the $12^{\text {th }}$ city.

Assumption 2. To use trade-weighted distance. The distance between the 11 Hebei cities used in the gravity model was determined using GIS techniques. For the distance between the $12^{\text {th }}$ city and the Hebei cities, it is obviously inappropriate to use the average distance from the capital cities of other provinces to the targeted Hebei cities; this would assume that the distances between any other place and the Hebei cities are the same. Therefore, we used the trade-weighted distance to estimate the distance from the $12^{\text {th }}$ city to the Hebei cities. First, we derived the distance between the 11 Hebei 
cities and the capital cities of the other 29 provinces or megacities from GIS. Next, we used the trade weight to adjust the distance. Because Hebei is one of the main exporters in China, we choose exports as an adjustment parameter. Specifically, we set the weight as the proportion of exports from Hebei to the other 29 provinces, which is derived from the 2012 China MRIO, and then applied the proportion to all 11 cities. Mathematically, this relationship can be expressed as follows:

$$
\mathrm{D}_{r}=\sum_{j} \frac{E_{j}^{H b}}{E_{T o t a l}^{H b}} \times D_{r j}
$$

$D_{r}$ denotes the trade-weighted distance between a Hebei city $\mathrm{r}$ and the $12^{\text {th }}$ city; $E_{j}^{H b}$ is the outflow from Hebei to another province $j$, and $E_{T o t a l}^{H b}$ is the total outflow from Hebei; and $D_{r j}$ is the distance from a Hebei city $r$ to the capital city of province $j$.

Assumption 3. Using trade flows between Hebei and adjacent provinces as a sample. Normally, sample data would be required to estimate these parameters, but trade data between cities was not available. Therefore, we followed the approach of (Nakano \& Nishimura, 2013; Yamada, 2015) and used transaction data from the 2012 China MRIO table as a proxy for sample data for each sector. Because our estimates are for the Hebei cities, we chose the transaction data between Hebei and the surrounding provinces or megacities (e.g., Beijing, Tianjin, Shanxi, and Shandong).

Due to the different sector classifications for the city IO table (42 sectors) and the 2012 China MRIO table (30 sectors), the parameters for the sectors that were aggregated in the MRIO table were assumed to be the same as those for the aggregated sectors. For example, the sectors of electricity and heating supply, gas supply and water supply in the city IO table are aggregated into one sector of electricity, heating, gas and water supply in the China MRIO table. Therefore, we set the parameters for these three sectors to be the same as for the national-level electricity heating, gas and water supply sector. The details of sector classification can be found in Mi et al. (2017).

\subsection{Reconciliation}

These calculations above yielded origin-destination matrix for each sector that we used as the initial matrix for RAS (bi-proportional techniques; see (Lahr \& de Mesnard, 2004), which used the set of the outflow and inflow constraints in the city IO tables for the 11 Hebei cities and the Hebei IO table for the "12th city". To ensure that the modelled trade flow matched the constraints, it should be subject to the following equations:

$$
\sum_{s=1}^{12} \mathrm{~T}_{i}^{r s}=\mathrm{T}_{i}^{r o}
$$

and 


$$
\sum_{r=1}^{12} \mathrm{~T}_{i}^{r s}=\mathrm{T}_{i}^{o s}
$$

Assuming that city $s$ has the same proportions for allocating the intermediate consumption and final consumption imported from city $r$, the balanced origin-destination matrix was used to distribute the trade matrix to the origin using the proportion $\mathrm{P}$, as follows:

$$
\mathrm{P}_{i}^{r s}=\frac{\mathrm{T}_{i}^{r s}}{\sum_{r=1}^{12} \mathrm{~T}_{i}^{r s}}
$$

The transaction matrix from city $r$ to city $s$ is displayed as follows:

$$
\left\{\begin{array}{l}
Z^{r s}=\mathrm{P}^{r s} \times Z^{o s} \\
F^{r s}=\mathrm{P}^{r s} \times F^{o s}
\end{array}\right.
$$

Where $Z^{o s}$ and $F^{o s}$ denote the imported matrices calculated before. Specifically, they can be expanded as follows:

$$
\begin{aligned}
& \left(\begin{array}{ccc}
Z_{11}^{r s} & \cdots & Z_{1,42}^{r s} \\
\vdots & \ddots & \vdots \\
Z_{42,1}^{r S} & \cdots & Z_{42,42}^{r s}
\end{array}\right)=\left(\begin{array}{ccc}
\mathrm{P}_{1}^{r S} & & \\
& \ddots & \\
& & \mathrm{P}_{42}^{r S}
\end{array}\right) \times\left(\begin{array}{ccc}
Z_{11}^{o s} & \cdots & Z_{1,42}^{o S} \\
\vdots & \ddots & \vdots \\
Z_{42,1}^{o s} & \cdots & Z_{42,42}^{o s}
\end{array}\right) \\
& \left(\begin{array}{ccc}
F_{11}^{r S} & \cdots & F_{1,5}^{r S} \\
\vdots & \ddots & \vdots \\
F_{42,1}^{r S} & \cdots & F_{42,5}^{r S}
\end{array}\right)=\left(\begin{array}{ccc}
\mathrm{P}_{1}^{r S} & & \\
& \ddots & \\
& & \mathrm{P}_{42}^{r S}
\end{array}\right) \times\left(\begin{array}{ccc}
F_{11}^{o S} & \cdots & F_{1,5}^{o S} \\
\vdots & \ddots & \vdots \\
F_{42,1}^{O S} & \cdots & F_{42,5}^{o S}
\end{array}\right)
\end{aligned}
$$

Thus, the off-diagonal trade flow for the 11 Hebei cities can be determined. For the other row, the inflow for the Hebei cities equals the inflow from the $12^{\text {th }}$ city, and imports for foreign countries can be directly summed to $Z_{f}$ and $F_{f}$ calculated above. Because the value added for the city-level MRIO table is identical to the city IO table, we can complete the vertical MRIO for each city. Because we proportionally allocate the trade matrix derived from the IO table to the other Hebei cities, the total inputs for each sector in the MRIO are identical to the IO table.

Although the total inputs for each city met the MRIO requirements, we found that the city outflow (horizontal sum) in this unbalanced MRIO was not the same as the modelled city outflow in the origin-destination matrix. Hence, we applied RAS to the raw trade transaction table that derives the city trade matrix using the raw MRIO, where the horizontal constraint of the total city outflow is the modelled origin-destination matrix and the vertical constraint is equal to the total inputs. Through these two RAS processes, we calculated the balanced MRIO table for the 11 Hebei cities, including the domestic intermediate matrix, inflows and outflows, imports and exports, and the value added, which were prepared previously. 


\section{Step 2: Linking and integrating city-level MRIO tables into a provincial-level MRIO table}

The next step is to nest the city-level MRIO tables constructed above into the 2012 provincial-level China MRIO (hereafter referred to as the China MRIO). In our framework, the city-level MRIO tables were compiled within the province and form part of the provincial MRIO table. Therefore, we can use the provincial-level MRIO as a platform to link the city-level MRIO tables. Before linking the citylevel MRIO tables with the provincial-level MRIO tables, the sectors must be reconciled, given that the sectors are expressed differently in the city-level MRIO tables (42 sectors) and the provinciallevel MRIO tables (30 sectors). We created a concordance matrix $\mathrm{C}$ to bridge the two sector classifications. Given two datasets (for example, A and B) with s and t classes respectively, the concordance matrix $\mathrm{C}$ will be an $\mathrm{s} \times \mathrm{t}$ matrix, with a value of 1 if the s-classed sectors belong to the $\mathrm{t}$ classed sectors and 0 if not. In this study, the $C$ matrix is a $30 \times 42$ matrix because we reconciled the 42 city-level MRIO sector classifications with the 30 provincial-level MRIO sector classifications.

To link the two MRIO tables, we allocated the inflow and outflow in the Hebei city-level MRIO table to the other 25 provinces and 4 megacities, using the China MRIO. We assumed that the sectorial structure of the 11 Hebei cities' inflows and outflows are the same as the structure of the Hebei province's inflows and outflows. In other words, the inflows (outflows) for the sectors of the 11 Hebei cities are distributed to other provinces and megacities in the same proportion as Hebei province's inflows (outflows) for those sectors. Mathematically, this follows equations (21) and (22):

$$
\begin{gathered}
\mathrm{IF}_{i}^{p c}=\widetilde{M}_{i}^{p h} \times \mathrm{IF}_{i}^{c} \\
\mathrm{OF}_{\mathrm{i}}^{\mathrm{cp}}=\mathrm{OF}_{i}^{c} \times \widetilde{\mathrm{E}}_{i}^{h p}
\end{gathered}
$$

Where $\mathrm{IF}_{i}^{p c}$ is the inflow from another province or megacity $p$ to the Hebei city $\mathrm{c}$, and $\mathrm{OF}_{\mathrm{i}}^{\mathrm{cp}}$ is the outflow from Hebei city $c$ to another province or megacity $p$ for sector $i . \widetilde{M}_{i}^{p h}$ is the inflow coefficient from another province or megacity $p$ to Hebei province $h$ for sector $i$, and $\widetilde{\mathrm{E}}_{i}^{h p}$ is the outflow coefficient from Hebei province $h$ to another province or megacity p, which can be derived from the China MRIO table. $\mathrm{IF}_{i}^{c}$ and $\mathrm{OF}_{i}^{c}$ are the inflow and outflow of Hebei city $c$ for sector $i$. For the final demand, the same process can be applied. Using the above calculations, we can replace the traction matrix for Hebei province with the traction matrix for the 11 Hebei cities' MRIO in the China MRIO table, including the intermediate matrix and final demand matrix. After removing the domestic matrix in the intermediate and final matrices, we can balance the new nested MRIO table using the modified RAS, preserving the transaction matrix of the non-Hebei matrix and setting the value equal to zero. In other words, RAS would only be used on the Hebei city transaction matrix using a set of constraints based on the Hebei inflows and outflows from the other 29 provinces or megacities in the China 2012 MRIO and the total intercity trade (inflows and outflows) derived from the Hebei city-level MRIO. By inserting the domestic matrix and adding value added, imports and exports, the nested city-level 
MRIO table can be completed with a total error/total output of 4\% (details seen in Supplementary). For the purpose of the Jing-Jin-Ji urban agglomeration MRIO table compilation, the final step is to aggregate the external regions to tailor the Jing-Jin-Ji region.

\section{Accounting Energy footprint at cities in Jing-Jin-Ji urban agglomeration}

We then apply the nested city-province MRIO table into the input-output analysis. Environmentally extended input-output model is employed in this study to calculate the energy footprint (Leontief, 1970). This approach has been widely applied to environmental footprint accounting (J. Meng et al., 2018; Serrano, Guan, Duarte, \& Paavola, 2016). The basic equation of input-output model can be expressed as:

$$
\mathbf{X}=\mathbf{A x}+\boldsymbol{F}
$$

Where $\mathrm{A}$ is the technical coefficient, and $\mathrm{F}$ is the total final demand by sector. Total output $\mathrm{X}$ can be expressed by Leontief inverse $\mathrm{L}$ as the followed equation:

$$
\mathbf{X}=(\mathbf{I}-\mathbf{A})^{-1} \boldsymbol{F}=\mathbf{L F}
$$

In MRIO framework, regions are connected through the interregional trade. The equation can be expressed in matrix form.

$$
\mathrm{X}=\left[\begin{array}{c}
X^{1} \\
X^{2} \\
\vdots \\
X^{n}
\end{array}\right], \mathrm{A}=\left[\begin{array}{cccc}
A^{11} & A^{12} & \ldots & A^{1 n} \\
A^{21} & A^{22} & \ldots & A^{2 n} \\
\vdots & \vdots & \ddots & \vdots \\
A^{n 1} & A^{n 2} & \ldots & A^{n n}
\end{array}\right], \mathrm{F}=\left[\begin{array}{cccc}
F^{11} & F^{12} & \ldots & F^{1 n} \\
F^{21} & F^{22} & \ldots & F^{2 n} \\
\vdots & \vdots & \ddots & \vdots \\
F^{n 1} & F^{n 2} & \ldots & F^{n n}
\end{array}\right]
$$

Where $\boldsymbol{X}^{\boldsymbol{n}}$ represents the total output of region n. The technical coefficient submatrix $\boldsymbol{A}^{r \boldsymbol{s}}=\left(\mathbf{z}_{\boldsymbol{i} \boldsymbol{j}}^{r \boldsymbol{s}} / \boldsymbol{x}_{\boldsymbol{j}}^{\boldsymbol{s}}\right)$ where $z_{i j}^{r s}$ represents intersectional monetary flows from sector $\mathrm{i}$ in region $\mathrm{r}$ to sector $\mathrm{j}$ in region $\mathrm{s}$, and the $\boldsymbol{x}_{j}^{\boldsymbol{s}}$ is the total output of sector $\mathrm{j}$ in region s. Similarly, $\boldsymbol{F}^{\boldsymbol{r} \boldsymbol{s}}=\boldsymbol{f}_{i}^{r \boldsymbol{s}}$ which represents the final demands of the region $\mathrm{s}$ in products of sector $\mathrm{i}$ in region $\mathrm{r}$.

To calculate energy use embodied in goods and services, the input-output model is extended by adding the environmental multiplier of energy intensity for each sector of each region. Energy use can be expressed as

$$
\mathbf{E}=\boldsymbol{w}(\mathbf{I}-\mathbf{A})^{-\mathbf{1}} \boldsymbol{F}
$$

Where $\mathbf{E}$ is the total energy use embodied in the goods and service to meet final demands, and $\mathbf{w}$ is a vector of energy intensity for all sectors in all regions.

\section{Results}

As one of the most important manufactory bases in China, Hebei cities play the role of providing energy-intensive but low value-added products for other cities, especially for their neighbouring 
Beijing and Tianjin that are the largest cities in North China. Therefore, to quantify the role of Hebei cities in the energy supply chain could have great implications, such as identifying which cities are more important in the supply chain. However, previous researches can only account the energy consumption or carbon emission at the province level with the provincial MRIO table. City-level MRIO table created in this paper could give further energy consumption details at city-level, and identify the key cities in energy use and the role of Hebei cities in China's energy supply chain. For the ease of presentation, we aggregate 40 regions into 19 regions based on the results of nested cityprovince MRIO, including Jing-Jin-Ji urban agglomeration (Beijing, Tianjin, and 11 Hebei cities), Northeast, Northwest, Central, Central Coast, Southeast, and Southwest for further analysis and discussion. Among them, only Beijing, Tianjin and coastal regions (Central Coast, and Southeast) are affluent, while inland regions (Hebei cities, Northeast, Northwest, Central, and Southwest) are less developed.

\section{The role of Hebei cities in energy footprint}

China has consumed the total energy of 1736 Mtce to sustain the socioeconomic development and meet the demands of consumption in 2012, in which $34 \%$ of total energy use is embodied in the interregional trade (586.4 Mtce). In China, a large amount of energy used embodied in goods and services for the developed regions are supplied from the less developed regions. 34\% of total energy use for developed regions are sourced from less developed regions (191.42 Mtce), in which the Central and Hebei cities are the largest exporter in trade-related energy. Energy use embodied in products and services exported from Hebei accounts for approximately $14 \%$ of total trade-related energy use in China (71.23 Mtce). The pattern of energy embodied in the inter-province trade has been investigated in previous researches(W. Chen, Wu, Lei, \& Li, 2017; Mi et al., 2017), and we focus on the city-level embodied energy next to make a demonstration for city-level MRIO. 

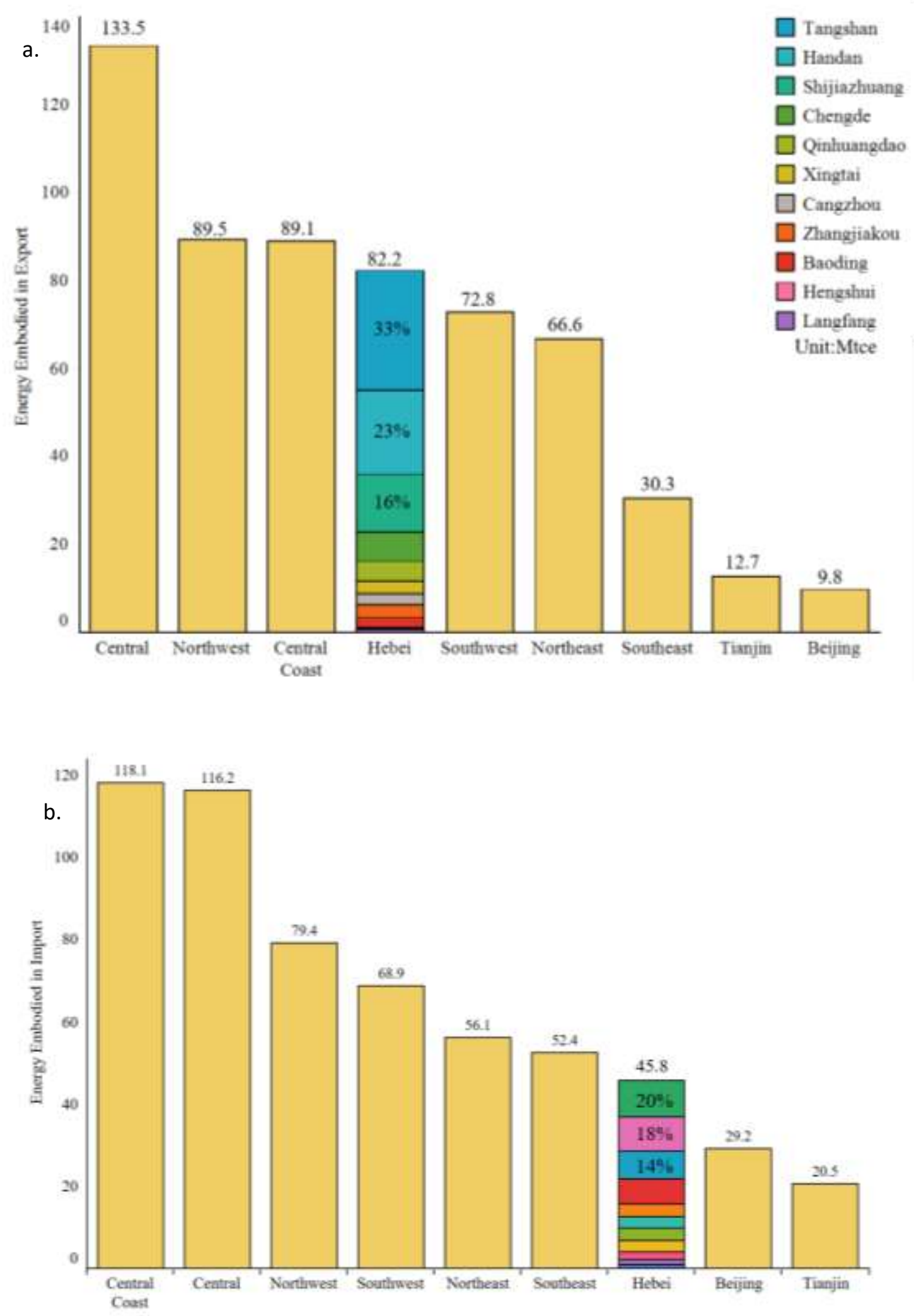

Figure 4. a). Energy use embodied in exports for the 19 regions or cities. b). Energy use embodied in imports for 19 regions or cities. The number on the top of the bar is the total energy use embodied in their exports. 
Among 11 Hebei cities, Tangshan, Handan and Shijiazhuang are main embodied energy exporters, accounting for $72 \%$ of total embodied energy exports from Hebei cities (Figure 4). Tangshan is the largest exporters in embodied energy (27.26 Mtce), accounting for 33.2\% of embodied energy exports from all Hebei cities, followed by Handan (18.91Mtce-23.0\%) and Shijiazhuang (13.26Mtce-16.1\%). In contrast, Hengshui and Langfang have the latest contribution in the energy embodied in trade, with only $0.5 \%$ and $0.7 \%$ of the total embodied energy flow from Hebei cities, respectively. However, less developed regions (Northeast, Northwest, Central, and Southwest) are the largest in importing embodied energy from Hebei cities, accounting for $49 \%$ of total energy use embodied in exports from Hebei cities (40.53 Mtce). Tangshan, Shijiazhuang, and Handan contribute the most, aggregately accounting for $74 \%$ of the total energy embodied in exports from Hebei cities.

In contrast, $27.6 \%$ of energy use for exports in Hebei cities (22.71 Mtce) is embodied in products consumed by coastal regions (central coast, and southeast) which are the most affluent regions in China. Similarly, Tangshan, Shijiazhuang and Handan are the largest exporters, aggregately accounting for $66 \%$ of energy embodied in products for coastal regions. Tangshan is the leading city with the contribution of $37.5 \%$ of total trade-related energy use for coastal regions (8.6 Mtce), followed by Handan (6.3 Mtce). Among coastal regions, central coasts account for $80 \%$ of imported embodied energy from Hebei cities (18.24 Mtce).

For Jing-Jin-Ji urban agglomeration, 18.99 Mtce of energy used in goods and services for their neighbouring cities are consumed by the cities of Jing-Jin-Ji urban agglomeration, with $23.1 \%$ of total energy embodied in export from Hebei cities. It is notable that $63 \%$ of energy embodied in exports to Jing-Jing-Ji urban agglomeration comes from Shijiazhuang, Tangshan, and Handan, with total 12.1 Mtce. Shijiazhuang takes the leading role from Tangshan and becomes the largest contributor with 25.3\%, followed by Tangshan (24.2\%), and Handan (14.4\%). As the largest cities in China, Beijing and Tianjin are the biggest consumers in Jing-Ji-Ji urban agglomeration. $19 \%$ of Beijing's imported embodied energy for consumption comes from 11 Hebei cities, in which $10.5 \%$ of the total embodied energy is from Tangshan (6.1\%), Shijiazhuang (3.5\%), Handan (3.7\%). For Tianjin, embodied energy from Hebei cities accounts for $14.4 \%$ of total imported embodied energy, with $10.3 \%$ from Tangshan (4.6\%), Shijiazhuang (2.7\%) and Handan (3.1\%).

\section{Energy use embodied in interregional trade}



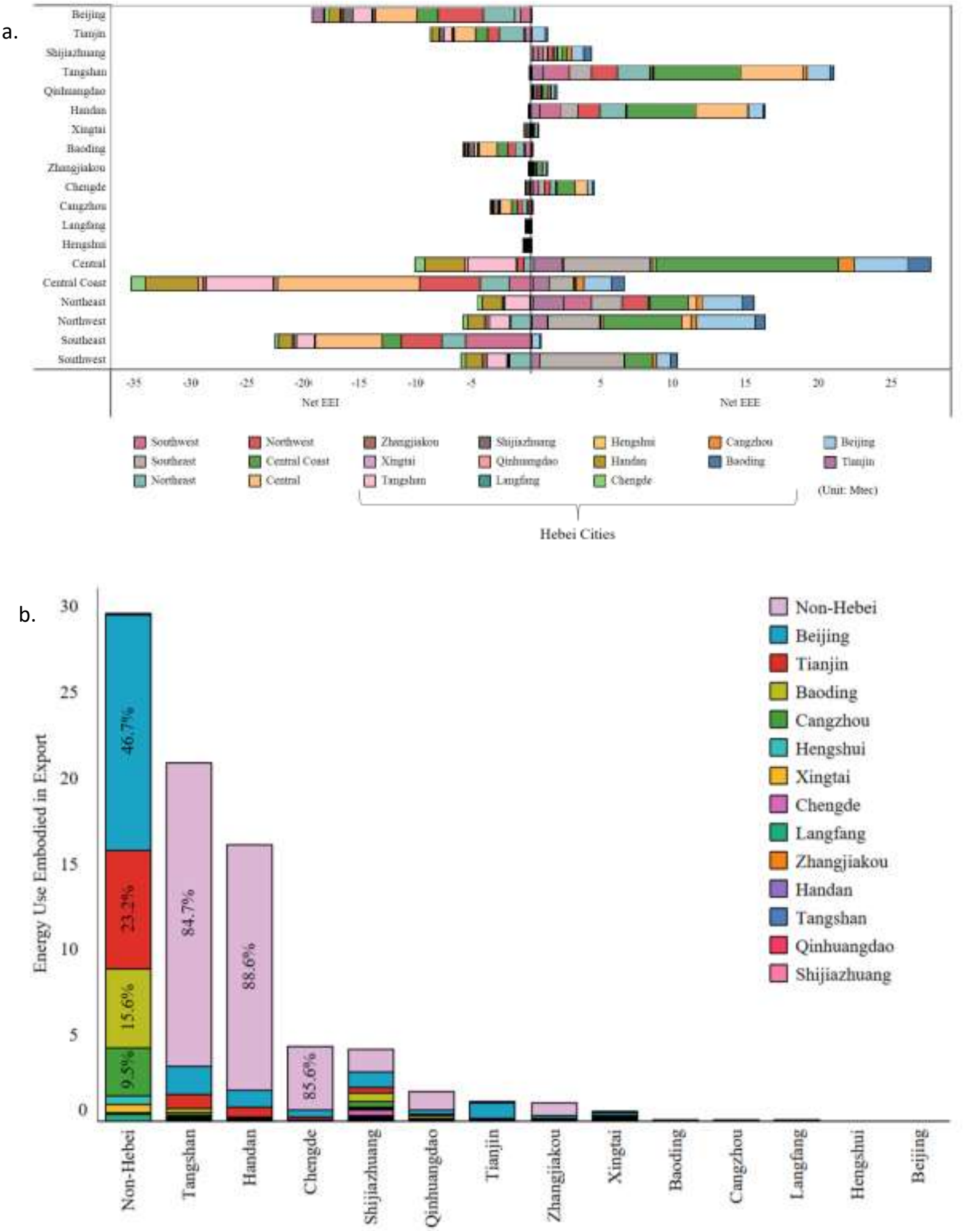

Figure 5 a). Energy use embodied in net trade for 19 regions or cities; b). Energy use embodied in net Import for Hebei cities and Non-Hebei regions.

Figure 5 shows energy embodied in net import (EEI) and energy embodied in net export (EEE) for 19 regions or cities. EEE and EEI are able to illustrate city or regions linkages in terms of energy use. Based on deficiency between EEI and EEE, all the 19 regions can be categorised into two groups: net 
importer and net exporter. Net importer in energy use embodied in trade are both affluent coastal regions, with EEI in these developed regions much larger than their EEE. At the city level, 6 cities in Hebei have net energy embodied in exports to Central coast, with total 13.02 Mtce of energy embodied in net exports, in which $83 \%$ are from Tangshan (6.0 Mtce) and Handan (4.7 Mtce). In contrast, the other 5 cities have net energy embodied in imports from Central coast instead, with 1.76 Mtce of energy use embodied in net imports. Baoding and Cangzhou are cities that import the most embodied energy from net trade, accounting for $84 \%$. For the Southeast coast, Central and Southwest make the largest contribution in the total energy use embodied in net imports, with 5.9 and 5.8 Mtce respectively. Although 7 cities have energy use embodied in net exports to the Southeast coast, Hebei cities have the less energy use embodied in exports to Southeast coast, with only 3.5 Mtce of traderelated energy use. Tangshan and Handan are still the largest contributors, with total 2.7 Mtce of net trade-related energy use (74\% of total energy use embodied in exports to the Southeast coast).

In contrast, Tangshan and Handan are leading suppliers with 4.34 Mtce and 3.57 Mtce of energy use embodied in net exports to the central region and aggregately accounting for $80 \%$ of central region's net embodied energy imports. For the Northwest, $69 \%$ of energy use embodied in net imports is from 6 Hebei cities, with Tangshan and Handan accounting for 54\%. However, 6 Hebei cities are the only suppliers in energy use embodied in imports to the Northeast. Similarly, the majority of energy embodied in net imports is from Tangshan and Handan.

In Jing-Jin-Ji cities, Beijing and Tianjin are dominant net importer with 19.39 Mtce and 7.77 Mtce of energy use embodied in net trade. Beijing has net energy use embodied in imports from all other regions or cities, while 14 of regions or cities supply Tianjin in energy use embodied in the net trade. Hebei cities are largest in the embodied energy imports to Beijing, with total 4.62 Mtce, followed by Northwest (3.98 Mtce) and Central (3.65 Mtce). For Tianjin, Northeast is the largest embodied energy use importer, with 2.15 Mtce, while Hebei cities have 1.84 Mtce of energy use embodied in net exports to Tianjin, ranking the third largest. In the Hebei cities, Tangshan, Handan, and Shijiazhuang are main suppliers for both Beijing and Tianjin, with 3.51 Mtce and 1.68 Mtce of energy embodied in net trade from these 3 cities respectively. Among 11 Hebei cities, 6 cities are net exporters in embodied energy in net trade, having 47.14 Mtce energy embodied in net trade, while other 5 net importer cities have energy use embodied in net imports from other regions. Tangshan and Handan are the most distinctive cities that contribute $77 \%$ of total exported energy use embodied in net trade, while Baoding and Cangzhou are the biggest net importers with 5.94 Mtce and 3.52 Mtce respectively. It is notable that Shijiazhuang has net exports for all other Jing-Jin-Ji cities, indicating Shijiazhuang is the basic supplier in energy use for the urban agglomeration.

\section{Discussion and Conclusion}


Our study presents a framework for compiling a city-level MRIO table using a bottom-up partialsurvey method and applies the MRIO table into city-level energy consumption accounting for the North China urban agglomeration or Jing-Jin-Ji urban agglomeration. Based on linking multiple layers, the framework breaks down the workload involved in dealing with large amounts of data into relatively small parts and then integrates the results by harmonisation based on a regional-level MRIO table. We used this framework to construct an MRIO table for 11 in cities in Hebei Province as well as an MRIO table for the Jing-Jin-Ji urban agglomeration. We also produced a nested Hebei-China MRIO table, which can be used as a platform for other cities. Although it represented a significant part of the city-level MRIO table construction, the Jing-Jin-Ji MRIO table compilation illustrates a simplified process for our framework due to data availability. Because Beijing and Tianjin were already included in the China interprovincial MRIO table, it was only necessary to replace Hebei Province with the Hebei city MRIO table in the China MRIO table. However, the case study still serves as a good demonstration of our method. The nested Hebei-China MRIO table we constructed in this study could be extended to other Chinese cities or even linked to global MRIO tables, based on the same assumption that the foreign trade coefficient for cities is the same as for China; this assumption has been made in previous studies (K. Feng et al., 2013; Mi et al., 2017). The tables constructed in this paper will be freely accessible through CEADS (http://www.ceads.net/). The case study in energy use embodied in trade for Jing-Jin-Ji urban agglomeration illustrates the distinctive patterns of energy use in energy use through the supply chain for every 11 cities, which implies the regional mitigation policies about energy use should be different in each city, especially for 6 net importer cities. In the supply side, policies in three key cities (Tangshan, Shijiazhuang, and Handan) should be particularly drawn attention by policymakers. The application of city-level energy footprint accounting demonstrates a single case of environmental accounting at city-level. The methodology to create the city-level MRIO table could undoubtedly encourage and inspire a wild range of studies that are able to concentrate on a city scale and make impacts on the research fields. However, as the definition and boundary of city is different in different countries, how to make consistency in the citylevel or sub-regional level could be a big challenge in either data collection or reconciliation. Therefore, the methodology applied in this paper mainly deal with the Chinese cities, which might be considered as sub-region in other countries.

Although our approach using a multiple-layer framework can provide a feasible way to compile a city-level MRIO table, there are still many challenges in limiting the wide application of this framework, as follows. 1). The city-level MRIO tables created in step 1 must be compiled by province because the city-level MRIO table will replace the province in the provincial-level MRIO table. The gravity model applied in the city-level MRIO compilation requires city IO tables for all the cities in the province; however, not every city compiled its single region IO table. For example, in some 
Chinese provinces, only 2 or 3 cities have IO tables. Given conflicting data between cities and provinces, simply subtracting the city IO data from the provincial IO data and categorising the remainder as "others" for cities without IO tables may not be appropriate; the residue is often negative. Creating new city IO tables and ensuring reasonable consistency between cities with IO tables could also be challenging. To tackle the challenge, an integrated way to combine the regionalisation technique with existing IO tables could be possible, but it still requires further exploration. 2). Stepwise city-level MRIO construction separates the task into pieces. However, as more city MRIO tables are added to a platform (the provincial MRIO table) and the modified RAS technique is applied, the requirements for computer memory will increase, resulting in very large workloads. Efficient working systems such as the cloud calculation platform used in IElab could be helpful. Future research should consider how to deal with these challenges and explore the feasibility of combining non-survey methods with the partial-survey method. Furthermore, based on the finding that larger IO transaction values have lower uncertainty (M Lenzen, Wood, \& Wiedmann, 2010), the uncertainty associated with multiple scale models should also be addressed with more cities in the MRIO table. Finally, we share the concern that the uncertainty may increase when a region is replaced by city-level (Bachmann et al., 2015).

\section{Reference}

Bachmann, C., Roorda, M. J., \& Kennedy, C. (2015). DEVELOPING A MULTI-SCALE MULTIREGION INPUT-OUTPUT MODEL. Economic Systems Research, 27(2), 172-193. https://doi.org/10.1080/09535314.2014.987730

Bonfiglio, A., \& Chelli, F. (2008). Assessing the behaviour of non-survey methods for constructing regional input-output tables through a Monte Carlo simulation. Economic Systems Research, 20(3), 243-258. https://doi.org/10.1080/09535310802344315

Caro, D., Rugani, B., Pulselli, F. M., \& Benetto, E. (2015). Implications of a consumer-based perspective for the estimation of GHG emissions: The illustrative case of Luxembourg. Science of the Total Environment, 508, 67-75. https://doi.org/10.1016/j.scitotenv.2014.11.053

Chavez, A., \& Ramaswami, A. (2013). Articulating a trans-boundary infrastructure supply chain greenhouse gas emission footprint for cities: Mathematical relationships and policy relevance. Energy Policy, 54, 376-384. https://doi.org/10.1016/j.enpol.2012.10.037

Chen, G. Q., Guo, S., Shao, L., Li, J. S., \& Chen, Z. M. (2013). Three-scale input-output modeling for urban economy: Carbon emission by Beijing 2007. Communications in Nonlinear Science and Numerical Simulation, 18(9), 2493-2506. https://doi.org/10.1016/j.cnsns.2012.12.029

Chen, W., Wu, S., Lei, Y., \& Li, S. (2017). Interprovincial transfer of embodied energy between the Jing-Jin-Ji area and other provinces in China: A quantification using interprovincial input-output model. Science of the Total Environment, 584-585, 990-1003. https://doi.org/10.1016/j.scitotenv.2017.01.152

Dhakal, S. (2010). GHG emissions from urbanization and opportunities for urban carbon mitigation. Current Opinion in Environmental Sustainability. https://doi.org/10.1016/j.cosust.2010.05.007

Dietzenbacher, E., Lenzen, M., Los, B., Guan, D., Lahr, M. L., Sancho, F., ... Yang, C. (2013). 
INPUT-OUTPUT ANALYSIS: THE NEXT 25 YEARS. Economic Systems Research, 25(4), 369-389. https://doi.org/10.1080/09535314.2013.846902

Dietzenbacher, E., Los, B., Stehrer, R., Timmer, M., \& de Vries, G. (2013). THE CONSTRUCTION OF WORLD INPUT-OUTPUT TABLES IN THE WIOD PROJECT. Economic Systems Research, 25(1), 71-98. https://doi.org/10.1080/09535314.2012.761180

Feng, K., Davis, S. J., Sun, L., Li, X., Guan, D., Liu, W., ... Hubacek, K. (2013). Outsourcing CO2 within China. Proceedings of the National Academy of Sciences, 110(28), 11654-11659. https://doi.org/10.1073/pnas.1219918110

Feng, K., Davis, S. J., Sun, L., Li, X., Guan, D., Liu, W., ... Hubacek, K. (2013). Outsourcing CO2 within China. Proceedings of the National Academy of Sciences, 110(28), 11654-11659. https://doi.org/10.1073/pnas.1219918110

Guan, D., Su, X., Zhang, Q., Peters, G. P., Liu, Z., Lei, Y., \& He, K. (2014). The socioeconomic drivers of China's primary PM2.5 emissions. Environmental Research Letters, 9(2). https://doi.org/10.1088/1748-9326/9/2/024010

Hebei Statistics Bureau. (2015). Hebei 2012 city input-output table. Shijiazhuang: Hebei Statistics Bureau.

Ichimura, S., \& Wang, H.-J. (2003). Interregional input-output analysis of the Chinese economy. World Scientific.

Kowalewksi, J. (2015). Regionalization of National Input???Output Tables: Empirical Evidence on the Use of the FLQ Formula. Regional Studies, 49(2), 240-250. https://doi.org/10.1080/00343404.2013.766318

Lahr, M. L. (1993). A Review of the Literature Supporting the Hybrid Approach to Constructing Regional Input-Output Models. Economic Systems Research, 5(3), 277-293. https://doi.org/10.1080/09535319300000023

Lahr, M. L., \& de Mesnard, L. (2004). Biproportional techniques in input-output analysis: Table updating and structural analysis. Economic Systems Research, 16(2), 115-134. https://doi.org/10.1080/0953531042000219259

Lau, L. J. (2010). Input-occupancy-output models of the non-competitive type and their application an examination of the China-US trade surplus. Social Sciences in China, 31(1), 35-54. https://doi.org/10.1080/02529200903565079

Lehtonen, O., \& Tykkyläinen, M. (2014). Estimating Regional Input Coefficients and Multipliers: Is the Choice of a Non-Survey Technique a Gamble? Regional Studies, 48(2), 382-399. article. https://doi.org/10.1080/00343404.2012.657619

Lenzen, M., Geschke, A., Malik, A., Fry, J., Lane, J., Wiedmann, T., ... Cadogan-Cowper, A. (2017). New multi-regional input-output databases for Australia-enabling timely and flexible regional analysis. Economic Systems Research, 29(2), 275-295.

https://doi.org/10.1080/09535314.2017.1315331

Lenzen, M., Geschke, A., Wiedmann, T., Lane, J., Anderson, N., Baynes, T., ... West, J. (2014). Compiling and using input-output frameworks through collaborative virtual laboratories. Science of the Total Environment, 485-486(1), 241-251. https://doi.org/10.1016/j.scitotenv.2014.03.062

Lenzen, M., Kanemoto, K., Moran, D., \& Geschke, A. (2012). Mapping the Structure of the World Economy. Environmental Science \& Technology, 46(15), 8374-8381. https://doi.org/10.1021/es300171x

Lenzen, M., Moran, D., Kanemoto, K., \& Geschke, A. (2013). BUILDING EORA: A GLOBAL MULTI-REGION INPUT-OUTPUT DATABASE AT HIGH COUNTRY AND SECTOR 
RESOLUTION. Economic Systems Research, 25(1), 20-49.

https://doi.org/10.1080/09535314.2013.769938

Lenzen, M., Wood, R., \& Wiedmann, T. (2010). Uncertainty Analysis for Multi-Region Input-Output Models - a Case Study of the UK's Carbon Footprint. Economic Systems Research, 22(1), 4363. https://doi.org/Pii 922158034\rDoi 10.1080/09535311003661226

Leontief, W. (1970). Environmental Repercussions and the Economic Structure: An Input-Output Approach. The Review of Economics and Statistics, 52(3), 262. https://doi.org/10.2307/1926294

Leontief, W., \& Strout, A. (1963). Multiregional Input-Output Analysis. In T. Barna (Ed.), Structural Interdependence and Economic Development: Proceedings of an International Conference on Input-Output Techniques, Geneva, September 1961 (pp. 119-150). inbook, London: Palgrave Macmillan UK. https://doi.org/10.1007/978-1-349-81634-7_8

Lin, J., Hu, Y., Cui, S., Kang, J., \& Ramaswami, A. (2015). Tracking urban carbon footprints from production and consumption perspectives. Environmental Research Letters, 10(5). https://doi.org/10.1088/1748-9326/10/5/054001

Liu, W., Li, X., Liu, H., Tang, Z., \& Guan, D. (2015). Estimating inter-regional trade flows in China: A sector-specific statistical model. Journal of Geographical Sciences, 25(10), 1247-1263. https://doi.org/10.1007/s11442-015-1231-6

Marto Sargento, A. L. (2007). Empirical Examination of the Gravity Model in two Different Contexts: Estimation and Explanation. Jahrbuch Für Regionalwissenschaft, 27(2), 103-127. https://doi.org/10.1007/s10037-007-0013-8

Meng, B., Zhang, Y., \& Inomata, S. (2013). COMPILATION AND APPLICATIONS OF IDEJETRO'S INTERNATIONAL INPUT-OUTPUT TABLES. Economic Systems Research, 25(1), 122-142. https://doi.org/10.1080/09535314.2012.761597

Meng, J., Liu, J., Guo, S., Huang, Y., \& Tao, S. (2016). The impact of domestic and foreign trade on energy-related PM emissions in Beijing. Applied Energy, 184, 853-862. https://doi.org/10.1016/j.apenergy.2015.09.082

Meng, J., Mi, Z., Guan, D., Li, J., Tao, S., Li, Y., ... Davis, S. J. (2018). The rise of South-South trade and its effect on global CO2 emissions. Nature Communications, 9(1), 1871. JOUR. https://doi.org/10.1038/s41467-018-04337-y

Mi, Z., Meng, J., Guan, D., Shan, Y., Song, M., Wei, Y.-M., ... Hubacek, K. (2017). Chinese CO2 emission flows have reversed since the global financial crisis. Nature Communications, 8(1), 1712. https://doi.org/10.1038/s41467-017-01820-w

Mi, Z., Zhang, Y., Guan, D., Shan, Y., Liu, Z., Cong, R., ... Wei, Y. M. (2016). Consumption-based emission accounting for Chinese cities. Applied Energy, 184, 1073-1081. https://doi.org/10.1016/j.apenergy.2016.06.094

Miller, R. E., \& Blair, P. D. (2009). Input - Output Analysis: Foundations and Extensions. Cambridge University Press, 784. https://doi.org/10.1017/CBO9780511626982

Minx, J., Baiocchi, G., Wiedmann, T., Barrett, J., Creutzig, F., Feng, K., ... Hubacek, K. (2013). Carbon footprints of cities and other human settlements in the UK. Environmental Research Letters, 8(3). https://doi.org/10.1088/1748-9326/8/3/035039

Moran, D., Keiichiro, K., Jiborn, M., Wood, R., Többen, J., \& Seto, K. C. (2018). Carbon footprints of 13,000 cities. Environmental Research Letters. JOUR. Retrieved from http://iopscience.iop.org/10.1088/1748-9326/aac72a

Nair, S., George, B., Malano, H. M., Arora, M., \& Nawarathna, B. (2014). Water-energy-greenhouse gas nexus of urban water systems: Review of concepts, state-of-art and methods. Resources, 
Conservation and Recycling. https://doi.org/10.1016/j.resconrec.2014.05.007

Nakano, S., \& Nishimura, K. (2013). A nonsurvey multiregional input-output estimation allowing cross-hauling: Partitioning two regions into three or more parts. Annals of Regional Science, 50(3), 935-951. https://doi.org/10.1007/s00168-012-0521-5

Oosterhaven, J. (2005). Spatial interpolation and disaggregation of multipliers. Geographical Analysis, 37(1), 69-84. https://doi.org/10.1111/j.1538-4632.2005.00522.x

Oosterhaven, J., Stelder, D., \& Inomata, S. (2008). Estimating international interindustry linkages: Non-survey simulations of the Asian-pacific economy. Economic Systems Research, 20(4), 395414. https://doi.org/10.1080/09535310802551448

Ou, J., Meng, J., Zheng, J., Mi, Z., Bian, Y., Yu, X., ... Guan, D. (2017). Demand-driven air pollutant emissions for a fast-developing region in China. Applied Energy, 204, 131-142. https://doi.org/10.1016/j.apenergy.2017.06.112

Paloheimo, E., \& Salmi, O. (2013). Evaluating the carbon emissions of the low carbon city: A novel approach for consumer based allocation. Cities, 30(1), 233-239. https://doi.org/10.1016/j.cities.2012.04.003

Peters, G. P., Andrew, R., \& Lennox, J. (2011). Constructing an environmentallyextended multiregional input-output table using the gtap database. Economic Systems Research, 23(2), 131152. https://doi.org/10.1080/09535314.2011.563234

Riddington, G., Gibson, H., \& Anderson, J. (2006). Comparison of gravity model, survey and location quotient-based local area tables and multipliers. Regional Studies, 40(9), 1069-1081. https://doi.org/10.1080/00343400601047374

Serrano, A., Guan, D., Duarte, R., \& Paavola, J. (2016). Virtual Water Flows in the EU27: A Consumption-based Approach. Journal of Industrial Ecology, 20(3), 547-558. https://doi.org/10.1111/jiec.12454

Shan, Y., Guan, D., Liu, J., Mi, Z., Liu, Z., Liu, J., ... Zhang, Q. (2017). Methodology and applications of city level CO2emission accounts in China. Journal of Cleaner Production, 161, 1215-1225. https://doi.org/10.1016/j.jclepro.2017.06.075

State Information Center. (2005). Interregional Input-Output Table for China. Beijing: Social Sciences Academic Press.

Temurshoev, U., Webb, C., \& Yamano, N. (2011). Projection of supply and use tables: Methods and their empirical assessment. Economic Systems Research, 23(1), 91-123. https://doi.org/10.1080/09535314.2010.534978

Wang, Y. (2017). An industrial ecology virtual framework for policy making in China. Economic Systems Research, 29(2), 252-274. https://doi.org/10.1080/09535314.2017.1313199

Wang, Y., Geschke, A., \& Lenzen, M. (2017). Constructing a Time Series of Nested Multiregion Input-Output Tables. International Regional Science Review, 40(5), 476-499. https://doi.org/10.1177/0160017615603596

Weber, C. L., Peters, G. P., Guan, D., \& Hubacek, K. (2008). The contribution of Chinese exports to climate change. Energy Policy, 36(9), 3572-3577. https://doi.org/10.1016/j.enpol.2008.06.009

Wiedmann, T. (2017). An input-output virtual laboratory in practice-survey of uptake, usage and applications of the first operational IELab. Economic Systems Research, 29(2), 296-312. https://doi.org/10.1080/09535314.2017.1283295

Wiedmann, T. O., Chen, G., \& Barrett, J. (2016). The Concept of City Carbon Maps: A Case Study of Melbourne, Australia. Journal of Industrial Ecology. https://doi.org/10.1111/jiec.12346 
Wiedmann, T., Wilting, H. C., Lenzen, M., Lutter, S., \& Palm, V. (2011). Quo Vadis MRIO? Methodological, data and institutional requirements for multi-region input-output analysis. Ecological Economics, 70(11), 1937-1945. https://doi.org/10.1016/j.ecolecon.2011.06.014

Xia, Y., Li, Y., Guan, D., Tinoco, D. M., Xia, J., Yan, Z., ... Huo, H. (2017). Assessment of the economic impacts of heat waves: A case study of Nanjing, China. Journal of Cleaner Production. https://doi.org/https://doi.org/10.1016/j.jclepro.2017.10.069

Yamada, M. (2015). Construction of a multi-regional input-output table for Nagoya metropolitan area, Japan. Journal of Economic Structures, 4(1), 11. article. https://doi.org/10.1186/s40008-015$0022-7$

Yu, Y., Hubacek, K., Feng, K., \& Guan, D. (2010). Assessing regional and global water footprints for the UK. Ecological Economics, 69(5), 1140-1147. https://doi.org/10.1016/j.ecolecon.2009.12.008

Zhang, Y., \& Qi, S. (2012). China Multi-Regional Input-Output Models. Beijing: China Statistics Press.

Zhang, Z., Shi, M., \& Zhao, Z. (2015). THE COMPILATION OF CHINA'S INTERREGIONAL INPUT-OUTPUT MODEL 2002. Economic Systems Research, 27(2), 238-256. article. https://doi.org/10.1080/09535314.2015.1040740

Zheng, H., Shan, Y., Mi, Z., Meng, J., Ou, J., Schroeder, H., \& Guan, D. (2018). How modifications of China's energy data affect carbon mitigation targets. Energy Policy, 116, 337-343. https://doi.org/10.1016/j.enpol.2018.02.031 